\title{
THE OPERATIVE TREATMENT OF THE FUNNEL CHEST*
}

\author{
BY

\section{F. REHBEIN and H.-H. WERNICKE} \\ From the Surgical Department of the Children's Hospital, Bremen, Germany
}

The operative correction of the funnel chest is a difficult and important problem. Quite a number of methods and modifications have been mentioned. Late results, however, do not always come up to expectation.

As a seriously deformed funnel chest may lead to troubles of the functions of the lungs and heart (Wegmann and Schaub, 1953; Schaub and Wegmann, 1954) operations should be limited to such cases only. Operating from a cosmetic point of view is not justified. The best age for a child to be operated on is 3 to 5 years. At this age we find an increased tendency to bronchitis, palpitation and delay of general physical development. Very serious disorders of the functions of the lungs and heart become evident in the second decade. On close examination of children under 10 years of age, we often found a reduction in maximum breathing capacity at this age too, as also did Brown and Cook (1951). An abnormal E.C.G. generally due to abnormal location of the heart was observed, too, with patients less than 10 years old. Operating at an early age is primarily a preventive measure.

In many cases surgery has been successfully performed in adults. The operation becomes more difficult because of greater rigidity. The result is mostly not so satisfactory as it would be with a child, but the patient is no longer endangered by growing factors.

The so-called limited, or ligament-cutting operation, at first used by Brown (1939) on infants, is not performed very often. Hausmann (1955) recommends the complete operation as early as the age of 2 years.

Quite irrespective of whatever method may be applied, the operation is divided into two parts: mobilization and stabilization. Methods differ, in particular in the course of stabilization, whereas with regard to mobilization variations to any great extent are not possible.

* Presented at the third annual meeting of the British Association of Paediatric Surgeons, London, July 17-19, 1956.
The substernal ligament or the tough fibrous attachments of the diaphragm and the linea alba to the point of the funnel must be stripped from the ribs to the extent of 2 to $4 \mathrm{~cm}$. each side of the sternum. The sternum is osteotomized in a wedgelike manner at the level of the gladiomanubrial junction. Splitting of the sternum, as recommended by Brunner (1954) and Gross (1953), will, when operating on a child, only be necessary if the sternum itself is shaped like a boat. Handling the costal cartilages varies greatly. Simple incisions, wedgelike or partial resections are recommended. Sauerbruch (1920), Brown (1939), Ochsner and DeBakey (1939) and Therkelsen (1951) have described extensive resections of the three or five lowest cartilages, either removing or preserving the perichondrium.

Though a fibrous stabilization or cartilage regeneration can be expected, it is not desirable to take away the frame from the thoracic wall to a larger extent than necessary. It will be sufficient after elevating the sternum to find out where the cartilage itself is deformed or where too much cartilage is present. Then it is resected step by step until the movable segments can be placed without any tension in the level of the elevated chest wall. In the event of the deformity being of an asymmetrical nature it will be necessary to remove larger segments on the steep side of the funnel.

The anterior chest wall can be fixed in different ways. According to Brown (1939) and Ravitch (1949, 1951, 1952), after completely resecting the cartilages bone suture in the range of wedge osteotomy will be sufficient to hold the sternum in the corrected position. The wire extension at the bottom of the sternum is disadvantageous. The danger of infection is not great but does exist. It may easily happen that too much pulling is caused. Furthermore pulling is only possible within the period of three to four weeks when the chest wall is not quite strong enough. In some cases we have seen new deformity after a good primary result. Once a depression of the sternum was found. In other cases the sternum moved forward out of the 
level of the chest wall and to the right and to the left the cartilages developed depressions.

Another way of stabilizing the chest wall is by placing a rib or cartilage under the sternum. This
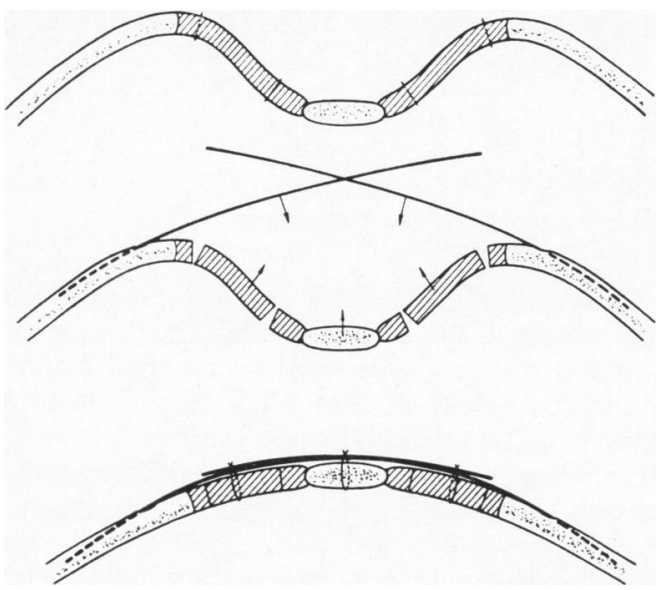

FIG. 1.-Stabilization of the elevated funnel chest with crossed metal blades.

procedure was applied by Dailey (1950), Sweet (1944) and Brodkin (1948). Rotation or removing the sternum is hardly practised today.

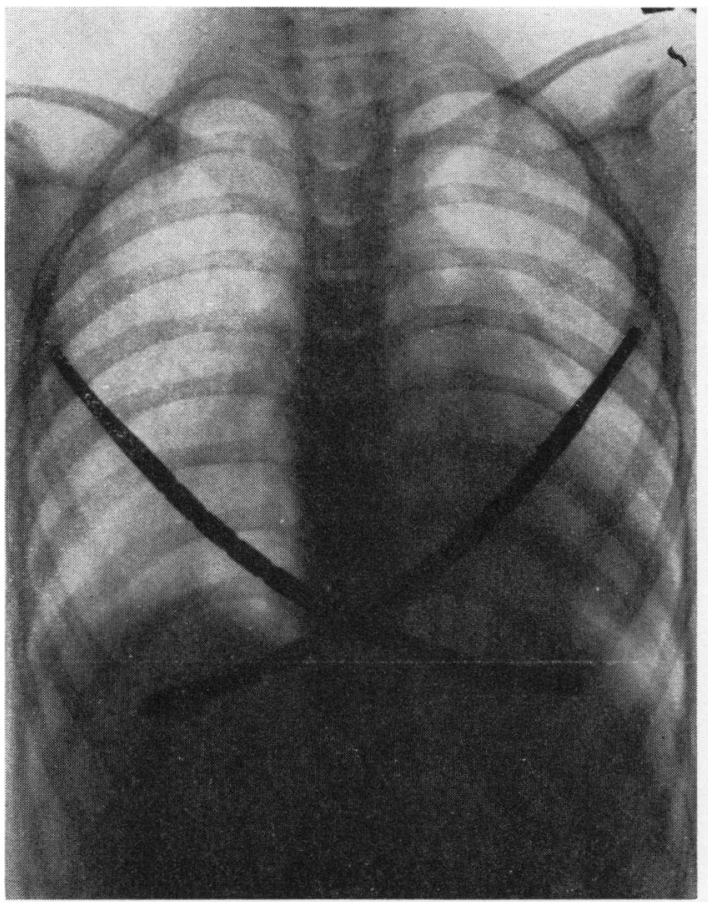

(a)

FIGS. $2 a$ and $2 b$.--Radiographs immediately after operation.
During the last 18 months we have applied in 12 cases a different way of stabilizing with children ranging from 4 to 14 years (Rehbein and Wernicke, 1955). After completing the mobilization narrow metal blades were pushed into the rib like a marrownail. The sternum and the cartilages are elevated, the blades crossed and depressed. The sternum is fixed with a wire sling at the crossing point elastically. The separate cartilage segments may also be suspended (Fig. 1). Costal cartilages which have been resected before to the necessary extent are now adapted loosely by means of sutures. Deformities of an asymmetrical type with an oblique sternum may be fixed also in this way. Only once was it necessary to split the sternum. The fixation is solid and stable, in particular when the metal blades reach to the other side. The chest wall cannot be depressed. It is suspended like a garland and splinted until completely healed. In operating on slightly deformed funnels one pair of blades will suffice (Fig. 2). In most cases we have used two pairs. In operating on deep funnels of older children three pairs will be necessary (Fig. 3).

As to complications, a pneumothorax on the right side has been noticed several times and can be removed easily by suction. The process of healing was uncomplicated in all cases. After operation the

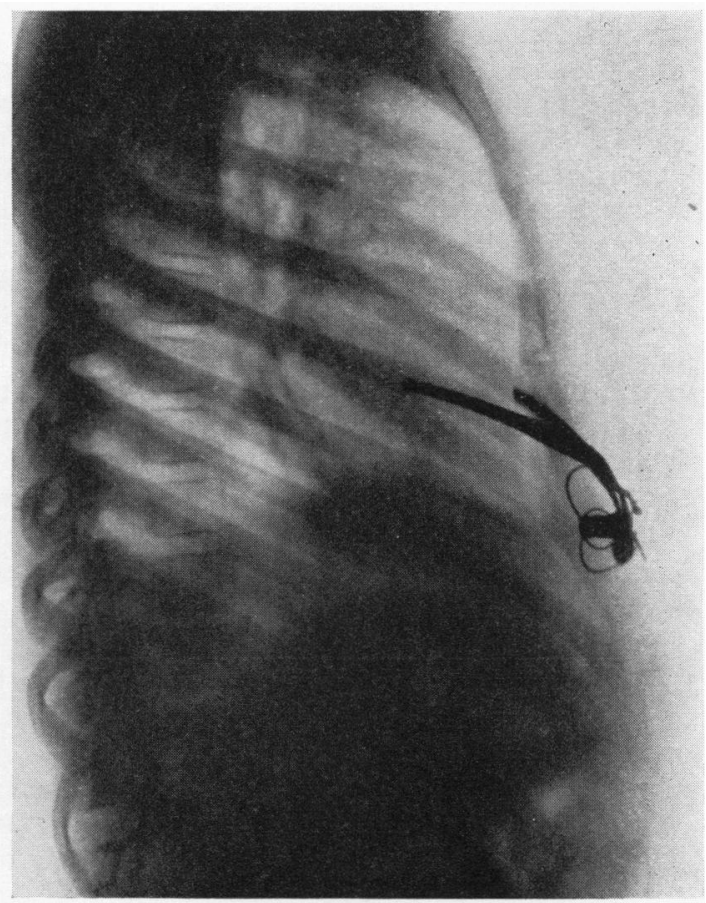

(b) 


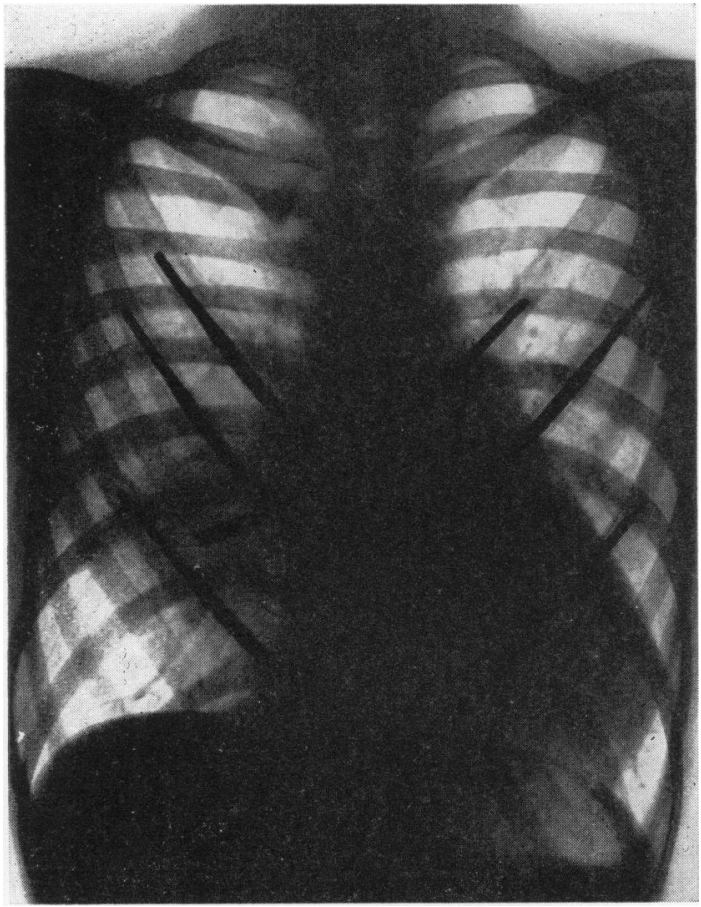

FIG. 3.-Fixation of the corrected anterior chest wall with three pairs of metal blades. Radiograph one year after operation.

children have to lie flat. Only after a few weeks' time are breathing exercises carried through as well as orthopaedic gymnastics, particularly directed to the back.

After six months the blades are removed. The result obtained by the operation is unchanged in most cases after the blades have been removed (Figs. 4

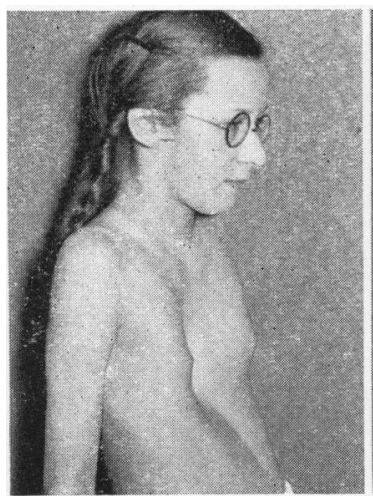

(a)

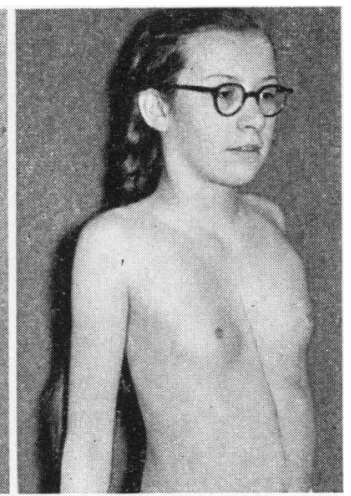

(b)
FIG. 4.-Girl, 12 years of age, (a) before the operation and (b) about 12 months after the operation (compare radiograph in Fig. 3.)

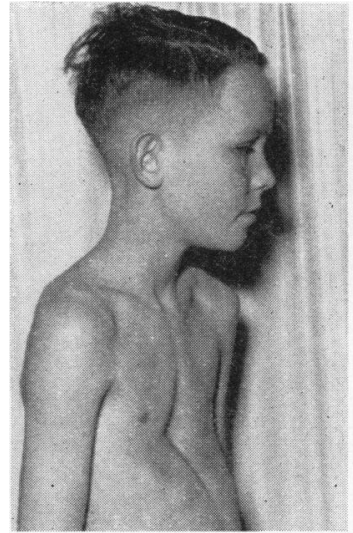

(a)

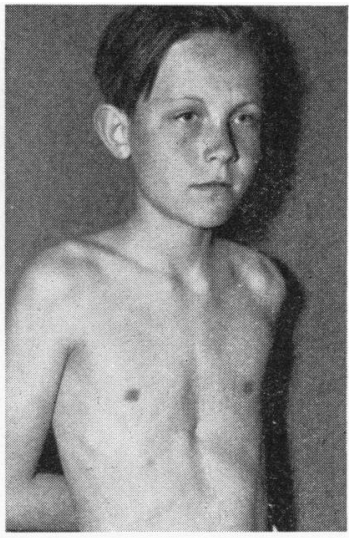

(b)
FIG, 5-Boy, 12 years old, (a) before the operation and (b) about 12 months after the operation.

and 5). The best results were obtained if there was a deep funnel, the edges of which were not far apart from each other (Fig. 6). If the antero-posterior flattening of the chest is considerable, a correction can only be effected within this particular level. In such a case in spite of splinting a slight depression remained.

The good results obtained without any splinting show that an additional procedure like this is not necessary in all cases. But if there is any uncertainty with regard to stabilization this modification may be a help. The advantage is that the blades may remain for any number of months, at the same time leaving immediately after operation the thorax solid and functioning perfectly. A slight disadvantage is that a second operation will be necessary to remove the blades, but this can be done by a small opening in the scar.

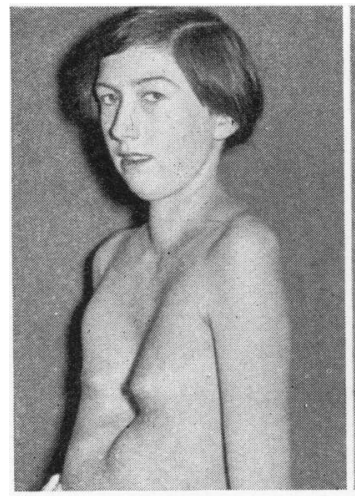

(a)

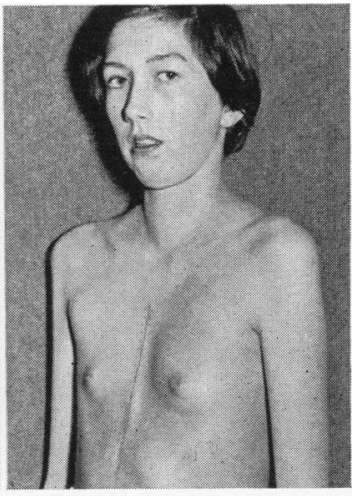

(b)
FIG. 6.-Girl, 14 years of age, (a) before the operation and (b) after the operation. 


\section{REFERENCES}

Brodkin, H. A. (1948). Amer. J. Surg., 75, 716

Brown, A. L. (1939), J. thorac. Surg., 9, 164

- and Cook, O. (1951). Dis. Chest., 20, 378.

Brunner, A. (1954). Chirurg., 25, 303.

Dailey, J. E. (1950). J. thorac. Surg., 19, 519.

Gross, R. E. (1953). The Surgery of Infancy and Childhood. Philadelphia and London.

Hausmann, P. F. (1955). J. thorac. Surg., 29, 636.

Ochsner, A., and DeBakey, M. (1939). Ibid., 8, 469.
Ravitch, M. M. (1949). Ann. Surg., 129, 429.

- (1951). Surgery, 30, 178. $23,138$.

Rehbein, F., and Wernicke, H.-H.(1955). Kinderärztl. Prax., 23, 126 Sauerbruch, F. (1920). Die Chirurgie der Brustorgane, Vol. I. Berlin.

Schaub, F., and Wegmann, T. (1954). Cardiologia (Basel), 24, 39.

Sweet, R. H. (1944). Ann. Surg., 119, 922.

Therkelsen, F. (1951). Acta chir. scand., 102, 36.

Wegmann, T., and Schaub, F. (1953). Schweiz. med. Wschr., 83, 986. 